\title{
PENFIGÓIDE CICATRICIAL: CONDUTA EM UM CENTRO DE
} REFERÊNCIA

\author{
$\underline{\text { Ádila dos Santos Bomfim }}{ }^{1}$; Tarsila de Carvalho Freitas Ramos ${ }^{2}$; Márcio Campos \\ Oliveira $^{3}$; Micheline Costa de Almeida ${ }^{4}$ \\ 1. Bolsista Voluntário, Graduanda em Odontologia, Universidade Estadual de Feira de Santana, e-mail: \\ adilabomfim@hotmail.com \\ 2. Professor do Curso de Odontologia, Departamento Saúde, Universidade Estadual de Feira de Santana, e-mail: \\ tarsilafreitas@yahoo.com.br \\ 3. Professor do Curso de Odontologia e Participante do Núcleo de Pesquisa em Câncer Oral, Departamento de Saúde, \\ Universidade Estadual de Feira de Santana, e-mail: \\ marciopatologiaoral@gmail.com \\ 4. Participante do Núcleo de Pesquisa em Câncer Oral, e Graduanda em Odontologia, Departamento de Saúde, \\ Universidade Estadual de Feira de Santana, e-mail: \\ $\underline{\text { michelinecostaodonto@gmail.com }}$
}

PALAVRAS-CHAVE: penfigóide cicatricial; paciente jovem; desordem auto-imune.

\section{INTRODUÇÃO}

O penfigóide cicatricial (PC), também denominado de Penfigóide da Membrana Mucosa Benigno e Penfigóide da Membrana Mucosa, é definido como uma doença autoimune, inflamatória e crônica. Acomete na maioria das vezes, adultos com média de 50 a 60 anos de idade, sendo as mulheres afetadas com mais frequência do que os homens. Apesar de acometer outras superfícies do corpo, a cavidade bucal tem sido descrita como o sítio de acometimento mais comum para essa patologia. O trabalho tem por objetivo relatar um caso de penfigóide cicatricial e a conduta adotada no Centro de Referência em Lesões Bucais (CRLB) da Universidade Estadual de Feira de Santana (UEFS), onde a paciente relatou a presença recorrente de lesões vesículo-bolhosas na região de gengiva inserida maxilar e mandibular, seguida de ulceração.

\section{METODOLOGIA}

Paciente com lesões orais em gengiva foi avaliada através de recursos semiotécnicos incluindo anamnese criteriosa buscando dados sobre a sua queixa principal e história da doença atual além de exame clínico cuidadoso no Ambulatório da Disciplina Estudos Integrados XIV. As lesões foram avaliadas clinicamente e dados a respeito da lesão fundamental foram colhidos e anotados em prontuário específico. Tais dados incluíram cor da lesão, tamanho, forma, localização anatômica e sintomatologia. Posteriormente foram solicitados exames complementares incluindo hemograma, glicemia em jejum e teste sorológicos para pesquisa de auto-anticorpos. Com todos os resultados em mãos, a biópsia incisional se fez necessária para a conclusão diagnóstica. Um fragmento da lesão foi removido cirurgicamente e enviado para exame anatomopatológico no Laboratório de Patologia Oral que compõe o Centro de Referência em Lesões Bucais da UEFS. Os prontuários da Disciplina trazem o Termo de Consentimento Livre e Esclarecido para que os pacientes se posicionem ou não como voluntários em pesquisas. 


\section{DISCUSSÃO}

Uma paciente do sexo feminino, 18 anos de idade, leucoderma, procurou o ambulatório do Centro de Referência em Lesões Bucais da UEFS com a queixa de "inflamação e sangramento gengival há oito meses". Ao ser interrogada sobre a história da doença atual, a paciente relatou a presença recorrente de lesões vesículo-bolhosas na região de gengiva inserida maxilar e mandibular, seguida de ulceração.

$\mathrm{Na}$ consulta, a mesma apresentou exames prévios com indicação de neutropenia e linfocitose, condições que a levaram à busca de um infectologista. $\mathrm{O}$ mesmo solicitou sorologia para vírus (HIV, HSV, HBV, HCV) e Sífilis, todos não reagentes. Com a suspeita diagnóstica de pênfigo vulgar, a biópsia incisional foi realizada na região de gengiva inserida entre as unidades dentárias 1.1 e 1.2 para a elucidação do caso através de exame histopatológico.

Os cortes histopatológicos corados e examinados em hematoxilina e eosina mostraram uma marcante divisão entre o epitélio de superfície e o tecido conjuntivo subjacente, constituindo uma fenda subepitelial, além de marcante infiltrado inflamatório crônico, o que corrobora com a literatura, conduzindo assim ao diagnóstico de penfigóide cicatricial. Após o diagnóstico, prescreveu-se prednisona $20 \mathrm{mg}$ durante 30 dias e a paciente foi encaminhada para tratamento da desordem autoimune em centro de referência e a um oftalmologista para avaliação da mucosa conjuntiva.

Por se tratar de uma doença sistêmica auto-imune, mucocutânea, bolhosa crônica causada por anticorpos contra a membrana basal, e acometer adultos idosos, na faixa etária de 50 a 60 anos, o relato chama a atenção no meio acadêmico e científico, por se tratar de uma paciente jovem de 18 anos, o que vai de encontro com a literatura.

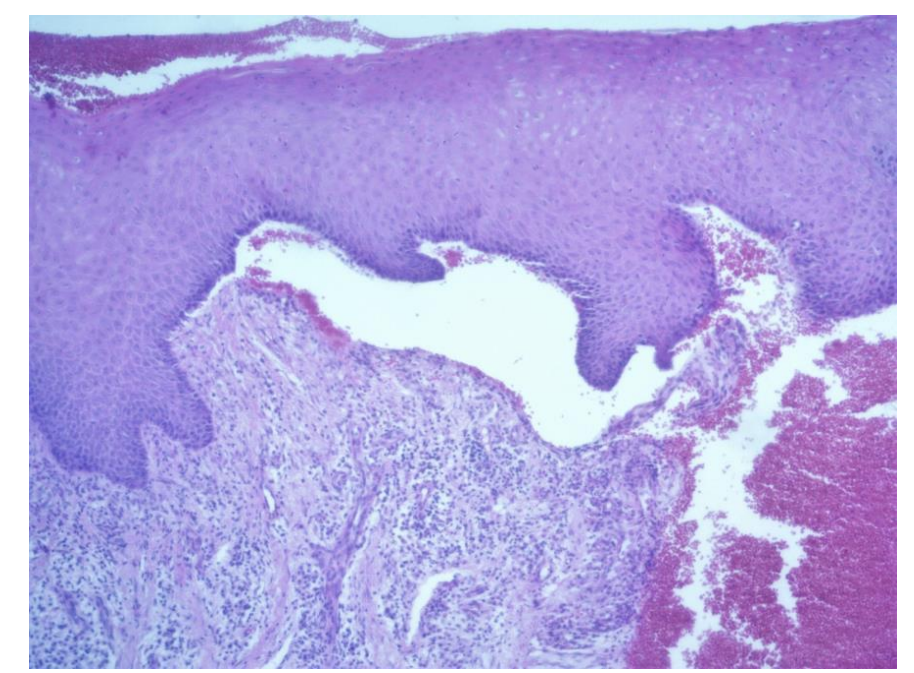

Figura 1: Fotomicrografia, evidenciando fenda subepitelial promovendo divisão entre o epitélio de superfície e o tecido conjuntivo subjacente, além de infiltrado crônico (Zeiss, objetiva 10x). 


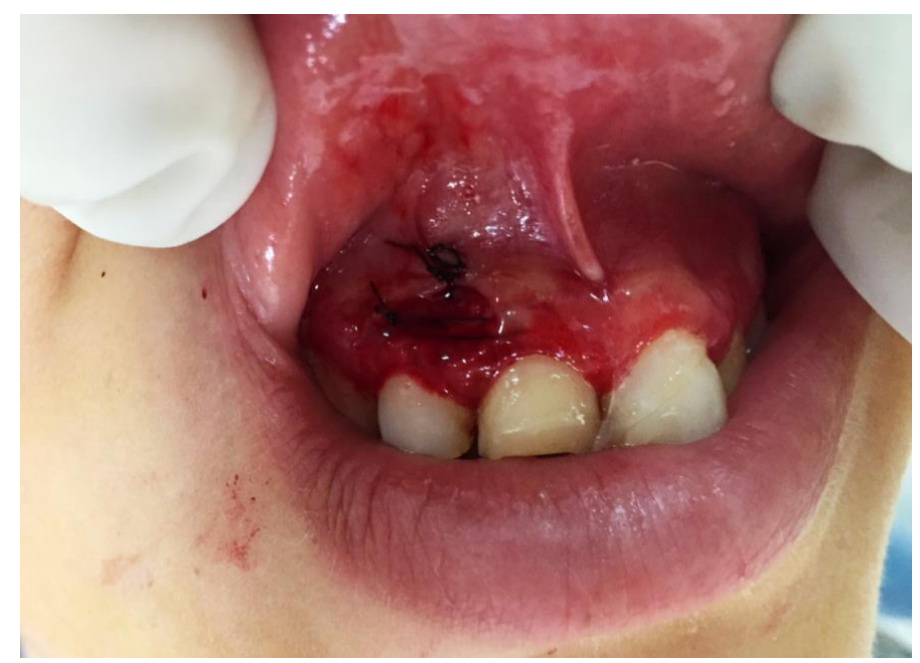

Figura 2: Biópsia incisional às margens da úlcera.

\section{CONSIDERAÇÕES FINAIS (ou Conclusão)}

Diante do exposto conclui-se que se trata de um caso clínico de relevância para o meio científico e acadêmico, uma vez que a paciente acometida é jovem, com idade de 18 anos no momento do diagnóstico. Podendo ainda ressaltar a importância do cirurgião-dentista no diagnóstico das desordens autoimunes, se fazendo extremamente necessário o conhecimento neste contexto e a sua importância no papel como promotor de saúde, para que seja estabelecido um diagnóstico precoce e um tratamento adequado. Nesse caso a elucidação diagnóstica foi conduzida pela equipe de Estomato-patologia do Centro de Referência em Lesões Bucais (CRLB).

\section{REFERÊNCIAS}

1. NEVILLE, Brad W, et al Patologia Oral \& Maxilofacial. 2. ed. Rio de Janeiro, RJ, 2004.

2. Odontol. Clín.-Cient., Recife, 9 (1) 83-87, jan./mar., 2010.

3. Revista Brasileira de Otorrinolaringologia 74 (6) Novembro/Dezembro 2008.

4. REVISTA FAIPE, v. 1, n. 2, jul./dez. 2011. 